${ }^{1}$ Program of Interactive Process of Organs and Systems, Federal University of Bahia.

${ }^{2}$ Institute of the Science of Health, Federal University of Bahia.
Corresponding author: Natália Nascimento Odilon. Av. Reitor Miguel Calmon, s/n, Canela, Salvador- Ba, CEP: 40110-902., $4^{\circ}$ andar, sala 413. e-mail:natalia.odi@gmail.com

Editor: Dr Altair A. Del Bel Cury

Received: November 23, 2020 Accepted: June 11, 2021

\section{The influence of the CIELAB parameters on the perception of color after the use of whitening toothpastes}

\author{
Natália Nascimento Odilon ${ }^{1, *}$ (iD), Rafaela Silva \\ Oliveira' ${ }^{1}$ Max José Pimenta Lima² ${ }^{2}$, Elisângela de \\ Jesus Campos ${ }^{2}$ iD
}

Aim: To evaluate the influence of the parameters $L^{*} a^{*} b^{*}$ on the variation of the color of bovine tooth enamel submitted to artificial darkening, after simulated brushing, with whitening toothpastes containing blue covarine. Methods: To undertake this study in vitro, 60 specimens (SP) were divided into 6 groups $(n=10)$ : control group (CGwater) and 5 test groups (GT1-Colgate Total 12, GT2-Oral-B 3D White Perfection, GT3Colgate Luminous Instant White, GT4-CloseUp White Diamond Attraction, GT5-Sorriso Xtreme White). The specimens were darkened with coffee and submitted to simulated brushing for 6,12 , and 24 months. The alteration in the color was evaluated using CIELAB parameters and the $\Delta \mathrm{L}, \Delta \mathrm{a}, \Delta \mathrm{b}$ and $\Delta \mathrm{E}$ were calculated. The data was analyzed through generalized linear models using the $\mathrm{R}$ program and considering a level of significance of $5 \%$. Results: The parameters $L^{*}, a^{*}$ and the $\Delta L$, $\triangle \mathrm{a}$ obtained better results in the test group than in the control group. There were no statistical differences between CG and the test groups for the evaluation of the $b^{\star}$ parameter. In the evaluation of the $\Delta b$, the GT3 differed statistically from the $\mathrm{CG}$. In relation to the $\triangle \mathrm{E}$, all the group tests showed a variation in color statistically greater than that of the CG and the GT4 showed the greatest variation, not differing from the GT3 during the periods studied. Conclusion: The mechanical and optical whitening agents positively influenced the values $L * a^{*}$ and $\mathrm{b}^{*}$, as well as in its variations and in the $\Delta \mathrm{E}$. It is important to emphasize, however, that to analyze tooth whitening it is necessary to evaluate their parameters together.

Keywords: Color. Tooth. Toothpastes. Bleaching agents. 


\section{Introduction}

Color is a perceptual phenomenon and, for that reason, subjective which depends on the observer, lights and object. Thus, with the purpose of establishing colorimetric criteria to quantify and describe this human perception, the Comission Internationale de I'Eclairage (CIE) defined color in three dimensions: luminosity or value, which is the luminosity relative to the color and encompasses the quantity of gray; the shade, the real color of the object such as green, red, blue and yellow; and chroma, which is the concentration or intensity of the shade ${ }^{1}$. CIE also instituted in 1976, the tridimensional space of color (CIELAB) in order to provide representation to perceptions of colored stimulate ${ }^{2}$.

CIELAB is defined numerically by three measurements: Luminosity $\left(L^{*}\right)$ which varies between 0 to 100; the $a^{*}$ coordinate, the red-green axis, which varies between -80 to +80 , and the $b^{*}$ coordinate, the yellow-blue axis, which varies between -80 to $+80^{2}$ The $L^{*}$ parameter corresponds to the luminosity, the closer it is to zero, the darker the object is and the closer to 100 the lighter it will be. Positive values of $b^{*}$ indicate yellow tones and negative $b^{\star}$ values indicate blue tones. And negative values of $a^{\star}$ indicate green tones, whereas positive values indicate red tones. Thus, the higher the value of $L^{*}$ and the lower the values of $a^{\star}$ and $b^{*}$, the tooth will be lighter and whiter ${ }^{1,3}$.

Since the tooth whitening occurs through the reduction of yellowing tones of the teeth, the alteration in the $b^{*}$ value seems to be the most important parameter to perceive the whitening, followed by the increase in the $L^{*}$ value and with less impact through the reduction of the value of $a^{\star}$. Further, through the CIELAB system, it is possible to determine the difference between two colors through the calculation of the numerical distance between the $L^{*} a^{*} b^{\star}$ coordinates, denominated as $\Delta E$, when evaluated together ${ }^{1,3,4}$.

Toothpastes with a whitening function have been developed to service the aesthetic demands of having whiter teeth. The most used whitening agents in toothpaste are mechanical agents (abrasives), chemical (peroxides) and optical (blue covarine). The abrasives, such as hydrated silica, calcium carbonate and mica, mechanically remove the teeth's extrinsic stains and are the most commonly used agents in toothpaste ${ }^{5}$ The chemical agents, such as hydrogen peroxide, oxidize the organic pigments located within the structure of the tooth, however their effects in toothpaste are considered limited due to their low concentration level and more importantly, hydrogen peroxide's instability in aqueous environments ${ }^{5,6}$. The use of the optical agent blue covarine, on the other hand, aims to modify the spectrum of absorption and reflection of light, altering the color of the shaft of the tooth from yellow to blue, decreasing the value of $b^{\star 7}$.

Blue Covarine-based toothpaste has been recommended for daily use, and produces an immediate whitening action after using it, fostering a gradual effect ${ }^{1,8}$. Together with the whitening agents, other agents that help to remove extrinsic stains such as anti-plaque and anti-calculus agents, surfactants and enzymes, as well as activated carbon, are also found in toothpaste $e^{5,9}$

Since the expected tooth whitening results from the removal of extrinsic pigments and stains, as well as the removal of optical agents, the changes in the teeth's coloration do not always correspond to the patient's expectations. Thus, it is important to 
perform studies that investigate the role of each of the parameters within the CIELAB system in the alteration of the teeth's color.

Given what has been outlined here, the objective of this study was to evaluate the influence of the $L^{*} a^{*} b^{*}$ parameters in the color variation of bovine dental enamel after simulated brushing with whitening toothpaste. The tested hypothesis evaluated was there are no difference among the groups regarding the $L^{\star} a^{\star} b^{\star}$ parameters.

\section{Materials and methods}

\section{Selection and preparation of the specimens}

To perform this study in vitro, 60 units of bovine incisors composed the specimens. Initially, the teeth were affixed and adapted in a precision cut-off machine (model ELSAW, ElQuip ${ }^{\circledR}$, São Paulo, SP, Brazil) and, with the aid of a diamond wheel (model ER04003 HC 4 × 0.012 × 1/2, ERIOS ${ }^{\circledR}$ equipment, São Paulo, SP, Brazil) were sectioned, separating the crown from the root of the dental units. From the crowns, cuts in the oral-lingual direction were made to obtain 60 fragments $(8 \mathrm{~mm} \times 8 \mathrm{~mm} \times 2 \mathrm{~mm})$ which were then flattened in a milling machine (Politriz metalográfica PL V060 Biopdi ${ }^{\circledR}$, São Carlos, SP, Brazil) on the oral surface, with the aid of water sanding discs in a sequence of granulation $(320,400,600,1200)$, in order to make the surfaces uniform and without the exposure of the enamel. Preparation of the specimens was finalized after they were fixed in Centerglass ${ }^{\circledR}$ orthophtalic resin. After polishing, the specimens were put into the L-200 ultrasonic cube (Schuster ${ }^{\circledR}$ Ltda.) for 10 minutes to remove any possible residues of polishing.

\section{Experimental Groups}

The 60 specimens were randomized and divided into 6 groups $(n=10)$, the control group (CG - water) and the test groups (GT1, GT2, GT3, GT4 e GT5) (Table 1). The main whitening agents present in the toothpastes are described in Table 2.

Table 1. Description of the test groups with the toothpastes.

\begin{tabular}{|c|c|c|c|}
\hline Groups & Toothpastes & Composition & Manufacturer \\
\hline GT1 & $\begin{array}{l}\text { Colgate } \\
\text { Total } 12\end{array}$ & $\begin{array}{l}\text { Sodium fluoride } 0,32 \% \text {, triclosan } 0,3 \% \text {, sorbitol, hydrated silica, } \\
\text { sodium laurylsulphatePVM/MA, carrageenan, sodium hydroxide, } \\
\text { sodium saccharin, titanium dioxide, limonene. }\end{array}$ & Colgate-Palmolive \\
\hline GT2 & $\begin{array}{l}\text { Oral-B } \\
\text { 3D White } \\
\text { Perfection }\end{array}$ & $\begin{array}{l}\text { Sodium fluoride (1100 ppm de flúor), glycerine, hydrated silica, } \\
\text { sodium hexametaphosphate, PEG-6, tisodium phosphate, } \\
\text { carrageenan, sodium lauryl sulphate, cocamidopropil betaine, } \\
\text { Mica (Cl 77019), sodium saccharin, PEG-20M, xanthum gum, } \\
\text { titanium dioxide (CI 77891), sucralose, limonene, CI74160. }\end{array}$ & $\begin{array}{c}\text { Procter \& Gamble } \\
\text { (P\&G) }\end{array}$ \\
\hline GT3 & $\begin{array}{l}\text { Colgate } \\
\text { Luminous } \\
\text { Instant } \\
\text { White }\end{array}$ & $\begin{array}{c}\text { Hydrated silica, sorbitol, glycerine, PEG-12, pentasodium } \\
\text { triphophate, tetrapotassium pyrophosphate, sodium } \\
\text { laurysuphate, aroma, taste, cellulose gum, cocamidopropil } \\
\text { betaine, sodium saccharin, xanthum gum, Sodium fluoride } \\
\text { (1100 ppm of flurine), sodium hydroxide, hidroxipropilmetil } \\
\text { cellulos, propilenglicol, polysorbate } 80, \text { mica, } \mathrm{Cl} 74160 \\
\text { (pigmento azul),CI77891, titanium dioxide, } \mathrm{Cl} 73360, \mathrm{Cl} 17200 \text {, } \\
\mathrm{Cl} 42051, \text { Eugenol. }\end{array}$ & Colgate-Palmolive \\
\hline
\end{tabular}




\begin{tabular}{|c|c|c|c|}
\hline Groups & Toothpastes & Composition & Manufacturer \\
\hline GT4 & $\begin{array}{l}\text { Close Up } \\
\text { Diamond } \\
\text { Attraction }\end{array}$ & $\begin{array}{c}\text { Sorbitol, Water, hydrated silica, sodium layryl sulphate, PeG-32, } \\
\text { Aroma, Sodium fluoride, cellulose gum, mica, Sodium saccharin, } \\
\text { trisodium phosphate, copolymen PVM/MA. }\end{array}$ & Unilever \\
\hline GT5 & $\begin{array}{l}\text { Sorriso } \\
\text { Xtreme } \\
\text { White } \\
\text { Evolution }\end{array}$ & $\begin{array}{l}\text { Hydrated silica, sorbitol, glycerine, peg-12, pentasodium } \\
\text { triphosphate, tetrapotássio pirophosphate tetrapottasium, } \\
\text { sodium lauryl sulphate, aroma, carboximetilcellulose, Sodium } \\
\text { fluoride, xanthum gum, sodium hydroxide, } \mathrm{Cl} 74160, \mathrm{Cl} 42090 \text {. }\end{array}$ & Colgate-Palmolive \\
\hline
\end{tabular}

Table 2. Principal whitening agents present in the toothpastes tested.

\begin{tabular}{lccc}
\hline Groups & Toothpastes & Mechanical & Optical \\
\hline GTI & Colgate Total 12 & Hydrated silica & - \\
\hline GT2 & Oral-B 3D White Perfection & $\begin{array}{c}\text { Hydrated silica } \\
\text { Mica }\end{array}$ & $\begin{array}{c}\text { Blue covarine } \\
\text { (Cl: 74160) }\end{array}$ \\
\hline GT3 & Colgate Luminous Instant White & $\begin{array}{c}\text { Hydrated silica } \\
\text { Mica }\end{array}$ & $\begin{array}{c}\text { Blue covarine } \\
\text { (Cl: 74160) }\end{array}$ \\
\hline GT4 & Close up Diamond Attraction- Power White & $\begin{array}{c}\text { Hydrated silica } \\
\text { Mica }\end{array}$ & $\begin{array}{c}\text { Blue covarine } \\
\text { (Cl: 74160) }\end{array}$ \\
\hline GT5 & Sorriso Xtreme White Evolution & Hydrated silica & $\begin{array}{c}\text { Blue covarine } \\
\text { (Cl: 74160) }\end{array}$ \\
\hline
\end{tabular}

\section{Darkening of the specimens}

After randomization, the specimens are kept immersed in soluble coffee solution (Nescafé, Nestlé ${ }^{\oplus}$, Brazil) at $37^{\circ} \mathrm{C}$, for 7 days, with daily changes according to the methodology proposed by Munchow et al. ${ }^{10}$ (2016). To prepare the coffee, the manufacturer's instructions were followed.

\section{Abrasion test}

Simulated brushing was performed at three intervals of time: 6 months ( 25,000 cycles), 12 months (50,000 cycles) and 24 months (100,000 cycles) with a brushing machine (ElQuip ${ }^{\oplus}$, São Paulo, SP, Brazil). The "heads" of the dental brushes with soft bristles (Classic Clean/Colgate-Palmolive Company ${ }^{\circledR}$ São Paulo, Brazil) were used for the brushing of the specimens. Toothpaste solutions were prepared (1:2) of slurry of toothpaste: water according to the Tao et al. ${ }^{11}$ (2017) and and submitted to $\mathrm{pH}$ verification (pHmetro Modelo 2000 Quimis ${ }^{\oplus}$ Aparelhos Científicos Ltda., São Paulo, Diadema, Brazil).

\section{Color evaluation}

Color alteration was evaluated by the Spectrophotometer Easyshade - Vita ${ }^{\circledR}$, which provides the readings for the CIE $L^{\star} a^{\star} b^{*}$. This system allows for the measurement of the difference in color between the two samples and shows the quantity of color alteration between the two readings $(\Delta \mathrm{E})$. Parameters for colors were obtained: before the beginning of the experiment, after the process of darkening and after the simulated brushing over the periods of 6,12 and 24 months. 
From the determinations of the CIELAB parameters, the $\Delta \mathrm{L}, \Delta \mathrm{a}, \Delta \mathrm{b}$ and $\Delta \mathrm{E}$ were calculated according to the following equation ${ }^{12}$ :

$\triangle \mathrm{L}:(\mathrm{L} 1-\mathrm{L} 0)$

$\triangle \mathrm{a}:(\mathrm{a} 1-\mathrm{a} 0)$

$\triangle \mathrm{b}:(\mathrm{b} 1-\mathrm{b} 0)$

$\Delta \mathrm{E}=\left[\left(\Delta \mathrm{L}^{\star}\right)^{2}+\left(\Delta \mathrm{a}^{\star}\right)^{2}+\left(\Delta \mathrm{b}^{\star}\right)^{2}\right]^{1 / 2}$

\section{Statistical Analysis}

Exploratory analysis indicated that the data did not meet the presuppositions of a parametric analysis and was analyzed through generalized linear models. The parameters $L * a * b *$ followed the model of repeated measurements in time, but as significant differences between the groups appeared at the beginning, this time was considered as a co-variable in these models. The $\Delta \mathrm{L}, \Delta \mathrm{a}, \Delta \mathrm{b}$ and $\Delta \mathrm{E}$ were also calculated at different intervals of time and generalized linear models were applied, since the data did not meet the presuppositions of ANOVA. Analyses were performed in the R program, considering the level of significance of $5 \%$.

\section{Results}

The results were analyzed using the CIELAB parameters and those of $\Delta \mathrm{L}, \Delta \mathrm{a}, \Delta \mathrm{b}$ and $\Delta \mathrm{E}$.

In relation to the $L^{*}$ parameter, all the test groups showed a value of $L^{*}$ higher than that of the control group in all periods of time studied. After 06 and 12 months of simulated bushing, the group GT2 showed the highest values of $L^{*}$, however it did not differ from GT1. After 24 months of simulated brushing, it was observed that the groups GT1 and GT2 showed higher values of L*, not differing significantly from GT3 and GT5 (Table 3).

Table 3. Median (minimum; maximum) of the variable relative to color (values $L$, $a$ and $b$ ) in function of group and time.

\begin{tabular}{|c|c|c|c|c|c|}
\hline \multirow{2}{*}{ Variable } & \multirow{2}{*}{ Group } & \multicolumn{4}{|c|}{ Time } \\
\hline & & ${ }^{1}$ Initial (Covariable) & ${ }^{2} 6$ months & ${ }^{3} 12$ months & ${ }^{4} 24$ months \\
\hline \multirow{6}{*}{ L } & CG & $55.15(39.40 ; 69.00)$ & $54.70(39.50 ; 69.70) \mathrm{Ad}$ & $56.60(38.20 ; 70.40) \mathrm{Ac}$ & 55.75 (37.80; 70.40) Ad \\
\hline & GT1 & $64.50(32.20 ; 71.10)$ & $74.95(42.90 ; 76.90) \mathrm{Ca}$ & 75.40 (45.10; 79.70) Ba & $78.35(51.90 ; 81.90) \mathrm{Aa}$ \\
\hline & GT2 & $66.30(55.00 ; 74.70)$ & $75.20(60.90 ; 85.40) \mathrm{Ba}$ & 77.25 (63.00; 86.30) Ba & $78.15(64.60 ; 87.00) \mathrm{Aa}$ \\
\hline & GT3 & $60.75(50.90 ; 74.70)$ & $74.00(50.60 ; 82.80) \mathrm{Cc}$ & $75.40(55.60 ; 86.40) \mathrm{Bab}$ & $76.90(69.50 ; 86.40) \mathrm{Aab}$ \\
\hline & GT4 & $49.05(25.80 ; 70.20)$ & $74.30(43.70 ; 87.90) \mathrm{Ab}$ & $71.00(62.20 ; 79.30) A b$ & $72.40(68.30 ; 79.30) \mathrm{Abc}$ \\
\hline & GT5 & $56.50(44.80 ; 67.40)$ & $71.45(53.50 ; 75.90) \mathrm{Cc}$ & 74.45 (58.90; 79.00) Bb & 75.40 (61.00; 81.50) Aab \\
\hline \multirow{6}{*}{$a^{*}$} & CG & $19.60(11.40 ; 25.80)$ & $17.35(11.16 ; 25.80) \mathrm{Aa}$ & $19.25(11.20 ; 26.40) \mathrm{Aa}$ & $19.40(11.10 ; 26.00) \mathrm{Aa}$ \\
\hline & GT1 & $12.15(7.40 ; 24.60)$ & $8.00(4.10 ; 21.40) \mathrm{Ae}$ & 7.05 (3.30; 24.10) Ad & $5.50(2.50 ; 21.70)$ Acd \\
\hline & GT2 & $11.15(4.50 ; 14.30)$ & $6.20(0.30 ; 9.80)$ Aef & $5.10(-0.10 ; 9.80) \mathrm{ABd}$ & $5.25(-0.40 ; 8.60) \mathrm{Bcd}$ \\
\hline & GT3 & $13.00(8.00 ; 20.60)$ & $5.95(3.70 ; 13.30)$ Af & $5.80(3.50 ; 13.20) \mathrm{Bd}$ & $4.90(1.50 ; 9.00) \mathrm{Cd}$ \\
\hline & GT4 & $21.65(9.00 ; 29.90)$ & $9.00(2.80 ; 24.20) \mathrm{Ad}$ & $9.25(5.70 ; 15.30) A b$ & $7.95(5.70 ; 11.20) A b$ \\
\hline & GT5 & $16.90(7.50 ; 23.20)$ & $10.45(4.80 ; 13.50) \mathrm{Ac}$ & $8.95(4.20 ; 12.70) \mathrm{Bbc}$ & $7.45(3.70 ; 11.80) \mathrm{Ccd}$ \\
\hline
\end{tabular}


Continuation

\begin{tabular}{|c|c|c|c|c|c|}
\hline \multirow{2}{*}{ Variable } & \multirow{2}{*}{ Group } & \multicolumn{4}{|c|}{ Time } \\
\hline & & ${ }^{1}$ Initial (Covariable) & ${ }^{2} 6$ months & ${ }^{3} 12$ months & ${ }^{4} 24$ months \\
\hline \multirow{6}{*}{$b^{*}$} & CG & $43.10(35.60 ; 48.20)$ & $42.30(35.30 ; 47.40) \mathrm{Aa}$ & $43.15(32.60 ; 47.30) \mathrm{Aa}$ & $43.10(33.20 ; 47.60) \mathrm{Aa}$ \\
\hline & GT1 & $43.85(29.30 ; 47.10)$ & $41.05(34.60 ; 44.60) \mathrm{Aa}$ & $39.80(34.90 ; 44.90)$ Aab & $38.55(34.20 ; 44.60)$ Aab \\
\hline & GT2 & $43.70(37.70 ; 45.60)$ & $39.65(30.80 ; 43.00) \mathrm{Aa}$ & $38.25(31.50 ; 43.10)$ Aab & $37.50(32.50 ; 42.40)$ Aab \\
\hline & GT3 & $43.65(40.50 ; 46.80)$ & $38.70(33.50 ; 43.90) \mathrm{Aa}$ & $38.55(33.00 ; 44.00)$ Aab & $37.00(34.30 ; 41.90)$ Aab \\
\hline & GT4 & $40.10(17.40 ; 44.90)$ & $37.95(33.60 ; 46.10) \mathrm{Ba}$ & $43.50(37.60 ; 51.00) \mathrm{Aa}$ & $42.90(36.00 ; 49.10) \mathrm{Aba}$ \\
\hline & GT5 & $43.05(40.00 ; 46.40)$ & $41.20(34.10 ; 46.70) \mathrm{Aa}$ & $41.40(34.70 ; 45.50) \mathrm{Aa}$ & $41.25(35.40 ; 45.10) \mathrm{Aab}$ \\
\hline
\end{tabular}

${ }^{1}$ Before brushing, ${ }^{2} 25,000$ cycles, ${ }^{3} 50,000$ cycles and ${ }^{4} 100,000$ cycles. Distinct letters (capital letters on the horizontal small letters on the vertical show the statistically significant differences $(p \leq 0.05)$.

Valor $L^{\star}$ : $p$ (grupo) $<0,0001 ; p$ (tempo) $=0,0002 ; p$ (interação) $=0,7009$

Valor $a^{*}: p$ (grupo) $=0,0031 ; p$ (tempo) $<0,0001 ; p($ interação $)=0,0049$

Valor $b *: p($ grupo $)=0,041 ; p($ tempo) $=0,0004 ; p$ (interação) $<0,0001$

Analyzing the $\Delta \mathrm{L}$ after 06,12 and 24 months of simulated brushing, all the test groups showed higher $\Delta \mathrm{L}$ than the CG. However there was no statistical difference in the three time periods studies between the test groups (Table 4).

Table 4. Median (minimum; maximum) of the variables relative to color $(\Delta \mathrm{L}, \Delta \mathrm{a}$ and $\Delta \mathrm{b})$ in function of group for each time interval.

\begin{tabular}{|c|c|c|c|c|}
\hline \multirow{2}{*}{ Variable } & \multirow{2}{*}{ Group } & \multicolumn{3}{|c|}{ Time } \\
\hline & & 0 to 6 months & 0 to 12 months & 0 to 24 months \\
\hline \multirow{7}{*}{$\Delta \mathrm{L}$} & CG & $0.40(-0.60 ; 5.50) c$ & $1.55(-1.20 ; 2.60) b$ & $0.50(-3.40 ; 2.80) b$ \\
\hline & GT1 & $10.00(5.80 ; 12.20) a b$ & $11.05(8.40 ; 14.00) a$ & 14.90 (10.30; 19.70)a \\
\hline & GT2 & $10.10(5.10 ; 13.50) a b$ & $11.55(4.40 ; 14.50) a$ & $11.65(9.60 ; 17.00) a$ \\
\hline & GT3 & $13.20(-8.40 ; 20.60) a b$ & $13.85(-3.40 ; 23.90) a$ & $16.10(10.50 ; 24.00) a$ \\
\hline & GT4 & $19.95(8.80 ; 35.10) a$ & $24.00(0.80 ; 49.40) a$ & $25.15(1.30 ; 50.90) a$ \\
\hline & GT5 & $12.65(0.10 ; 24.00) a b$ & $14.10(5.50 ; 30.90) a$ & $15.00(7.60 ; 29.80) a$ \\
\hline & p-value & $<0.0001$ & 0.0009 & 0.0003 \\
\hline \multirow{7}{*}{$\Delta \mathrm{a}$} & CG & $-0.07(-7.30 ; 1.23) a$ & $-0.20(-1.50 ; 0.90) a$ & $0.10(-2.50 ; 1.60) a$ \\
\hline & GT1 & $-3.90(-6.00 ;-3.00) a b$ & $-5.20(-6.70 ;-0.50) a b$ & $-6.05(-8.60 ;-2.90) a b$ \\
\hline & GT2 & $-4.60(-5.60 ;-3.00) b$ & $-4.55(-7.50 ;-2.80) a b$ & $-5.30(-7.50 ;-2.40) a b$ \\
\hline & GT3 & $-5.70(-11.00 ;-0.10) b$ & $-5.80(-11.90 ;-1.80) b$ & $-6.90(-12.60 ;-5.60) b$ \\
\hline & GT4 & $-7.90(-17.40 ; 1.20) b$ & $-10.55(-22.20 ; 3.10) b$ & $-12.65(-22.60 ; 2.10) b$ \\
\hline & GT5 & $-4.55(-11.70 ;-1.90) b$ & $-5.95(-13.80 ;-2.90) b$ & $-6.60(-14.90 ;-3.80) b$ \\
\hline & p-value & 0.0004 & 0.0007 & 0.0003 \\
\hline \multirow{7}{*}{$\Delta \mathrm{b}$} & CG & $-0.55(-1.70 ; 2.00) a b$ & $-0.10(-3.00 ; 1.40) a b$ & $-0.60(-3.50 ; 1.30) a b$ \\
\hline & GT1 & $-2.80(-3.80 ; 5.30) a b c$ & $-3.95(-5.20 ; 9.60) a b c$ & $-5.80(-7.80 ; 12.10) b c$ \\
\hline & GT2 & $-3.95(-6.90 ;-2.10) b c$ & $-4.65(-7.30 ;-1.50) b c$ & $-4.75(-7.10 ;-1.70) b c$ \\
\hline & GT3 & $-5.05(-7.10 ;-1.70) c$ & $-5.35(-9.40 ;-1.60) c$ & $-6.25(-9.00 ;-0.70) c$ \\
\hline & GT4 & $0.35(-11.30 ; 20.60) a b c$ & $2.95(-2.20 ; 28.10) a$ & $3.15(-1.80 ; 26.80) a$ \\
\hline & GT5 & $-1.55(-17.80 ; 15.70) a b c$ & $-2.20(-18.90 ; 15.90) a b c$ & $-1.95(-19.00 ; 16.90) a b c$ \\
\hline & $\mathrm{p}$-value & 0.0004 & $<0.0001$ & $<0.0001$ \\
\hline
\end{tabular}

*Distinct letters on the vertical side indicate statistically significant differences $(p \leq 0.05)$. 
In relation to the $a^{*}$ parameter, all the test groups showed lower $a^{*}$ values than that of CG in the three periods studied. Comparing the groups, after 06 months of simulated brushing, the GT3 group showed a lower value of $a^{\star}$, not differing significantly from GT2. After a period of 12 months, the GT2 group showed a lower value of a*, not differing statistically from GT1 and GT3. And after 24 months of simulated brushing, the GT3 showed a lower value of $a^{\star}$, not differing statistically from GT1, GT2 and GT5 (Table 3).

In relation to $\Delta$ a, over the interval of 0-6 months, all the groups showed a $\Delta$ a statistically greater than that of the control group except GT1. Over the period of 0-12 months and 0-24 months, the groups GT3, GT4 and GT5 showed a $\triangle$ a statistically higher than that of CG (Table 4).

In relation to the $b^{*}$ parameter, after the periods of 06,12 , and 24 months of simulated brushing, there were no statistical differences between the CG and test groups (Table 3). As to the $\triangle b$, in the three periods of time studied, it was observed that the GT3 showed a higher $\triangle b$ and was the only group which differed statistically from the CG (Table 4).

In the time intervals of 0-6, 0-12 and 0-24 months, all the groups presented a $\Delta E$ significantly higher than that of the CG. The GT4 group showed a higher $\Delta E$, not differing statistically from GT3 in the three periods of times studied and from the GT5 at the interval of 0-6 months (Table 5).

Table 5. Median (minimum; maximum) of $\Delta \mathrm{E}$.

\begin{tabular}{lccc}
\hline \multirow{2}{*}{ roup } & \multicolumn{3}{c}{ Time } \\
\cline { 2 - 4 } & $\mathbf{0}$ to $\mathbf{6}$ months & 0 to 12 months & 0 to 24 months \\
\hline CG & $1.38(0.33 ; 8.19) \mathrm{c}$ & $2.29(0.86 ; 3.31) \mathrm{c}$ & $2.08(1.21 ; 4.89) \mathrm{c}$ \\
\hline GT1 & $11.40(7.45 ; 13.61) \mathrm{b}$ & $13.02(10.22 ; 16.09) \mathrm{b}$ & $17.33(12.54 ; 23.30) \mathrm{b}$ \\
\hline GT2 & $11.82(7.71 ; 15.21) \mathrm{b}$ & $13.43(7.21 ; 15.84) \mathrm{b}$ & $14.05(11.11 ; 19.05) \mathrm{b}$ \\
\hline GT3 & $15.00(9.14 ; 23.72) \mathrm{ab}$ & $16.06(8.43 ; 27.09) \mathrm{ab}$ & $18.74(13.82 ; 27.85) \mathrm{ab}$ \\
\hline GT4 & $22.37(11.19 ; 39.18) \mathrm{a}$ & $26.83(7.16 ; 61.01) \mathrm{a}$ & $27.84(5.58 ; 61.80) \mathrm{a}$ \\
\hline GT5 & $14.91(3.34 ; 26.88) \mathrm{ab}$ & $15.99(8.41 ; 33.77) \mathrm{ab}$ & $16.38(11.44 ; 33.16) \mathrm{b}$ \\
\hline p-value & $<0.0001$ & 0.0001 & 0.0001 \\
\hline
\end{tabular}

* Distinct letters on the vertical side show the statistically significant differences $(p \leq 0.05)$

\section{Discussion}

The literature relative to the evaluation of color through the individual parameters of CIELAB demonstrates that the perception of dental whitening occurs with the increase of $L^{\star}$, decrease of $b^{\star}$ and to a lesser degree the decrease in the $a^{\star}$ parameter ${ }^{1,8}$.

The whitening agents can be incorporated into toothpastes to be used for daily oral hygiene. In general, whitening toothpastes promote teeth whitening through the abrasive removal of the extrinsic stains on the enamel ${ }^{13}$. The abrasives have the capacity to polish the surface of the enamel, according to the format and size of the abrasive particles, resulting in surface smoothness and an increase in the luminosity of the surface of the tooth ${ }^{14}$, directly influencing the value of the $L^{*}$ parameter of the CIELAB system, which represents the luminosity of the surface. 
In the present study, all the whitening toothpastes and for conventional use have the mechanical agent hydrated silica isolated or associated with mica, in their formulation. This suggests that the presence of abrasives results in the polishing of the surface of the specimens, increases shine, and thus justifies the greater $\Delta L$ observed in the test groups, even those brushed with conventional use toothpaste. However, different concentrations, shapes and sizes of the abrasive particles present in the toothpastes can explain the different values of luminosity in each group when evaluating the $L *$ parameter in an isolated manner.

The parameter $a^{\star}$ considers the pivot of the red-green color, so after dental whitening there is a reduction in the value of $a^{*}$. However, according to the literature, this parameter has less influence on the perception of tooth whitening ${ }^{3,15}$. In the current study, all the test groups showed lower values for $a^{\star}$ than the control group. This finding can also be justified by the presence of mechanical agents in all the toothpastes evaluated which resulted in the removal of extrinsic stains on the enamel.

Studies affirm that the reduction in the $b^{*}$ parameter is the most important factor for perception of tooth whitening, principally when the optical whitening agent blue covarine is used $^{1,3}$. In the current study, when the $b^{*}$ parameter was evaluated in an isolated manner, there was no difference observed between the test groups and the control group. However, in $\triangle b$, only the GT3 differed statistically from the control group in all the intervals of time studied. Analysis of the formulation of GT3's toothpaste showed the presence of two mechanical whitening agents, hydrated silica and mica, as well as blue covarine and the blue pigment evident, which when associated, seems to result in a whitening effect ${ }^{3}$.

In addition to the abrasive agents, surfactant active and anti-plaque/anti-calculus agents help in tooth whitening. The surface-active agents act by removing the hydrophobic compounds from the surface of the tooth, while the anti-plaque/anti-calculus agents prevent deposit of the chromophores on the surface of the enamel and inhibit the formation of calculus, where the formation of extrinsic stains could occur ${ }^{5}$.

The GT3 group was the only one to show two surface active agents and three anti-calculus agents simultaneously in its composition. According to the literature, sodium laurylsulphate ${ }^{5,16}$ and cocamidopropil betaine ${ }^{16}$ are the surface active and the anti-calculus agents are pentasodium triphosphate ${ }^{5,16}$, tetrapotassium pyrophosphate ${ }^{5,16}$ and sodium hydroxide ${ }^{16}$. Thus, the composition of the mechanical and optical whitening agents and agents which aid in the whitening present in the formulation of toothpastes of the GT3 seems to explain the results observed in this group.

The $\Delta E$ represents the variation of color of the same object from those of $\Delta \mathrm{L}, \Delta \mathrm{a}, \Delta \mathrm{b}$ calculated together ${ }^{12}$. In the current study, all the test groups showed significantly higher $\triangle \mathrm{E}$ than the control group, and this finding could be justified by the presence of the mechanical agent hydrated silica which is present in all the whitening toothpastes and for conventional use. However, in the comparison between the test groups, only GT4 differed from GT1, the group brushed with all the whitening toothpastes and for conventional use toothpaste. Such a finding can be justified by the different concentrations of whitening agents present in their formulations. However, due to the patent rights of the manufacturers, access to the detailed information about the composition of the toothpastes is limited. Thus, conclusive comparisons could not be undertaken ${ }^{17}$. 
The literature is controversial in relation to the influence of the CIELAB parameters on the perception of the color alteration when evaluated separately. Some authors report that the $b^{*}$ parameter is the most important for tooth whitening 7,18 , while other authors observe greater alteration in the $L^{*}$ parameter after whitening ${ }^{19,20}$. Further, there are studies which point out that the results of the three parameters influence in the same way for whitening 21,22 . However, when analyzing the results of the studies, the fact that the research was performed using different methodologies, different types of whitening materials, agents and methods should be taken into consideration, and therefore there was no consensus in the literature. In the current study, it was observed that in the GT4 group, which had the greatest variation in color, the parameters which were most prominent were the $\Delta \mathrm{L}$ and $\Delta \mathrm{a}$, suggesting that these parameters had more influence on the result than $\Delta \mathrm{E}$.

In light of this, it is possible to conclude that the simulated brushing of the bovine enamel with the whitening and conventional toothpastes promoted a whitening effect, mainly due to the presence of abrasive and mechanical agents, and that the presence of other components in the formulation seems to help in the removal of extrinsic stains.

In conclusion, mechanical whitening and optical agents influence the values of $L^{*} a^{*}$ and $b^{\star}$, as well as their variations in $\triangle E$, after simulated brushing, resulting in improvement in the color of bovine enamel. However, it is important to emphasize that to analyze dental whitening through the CIELAB system, it is necessary to evaluate the parameters together.

\section{Conflicts of interest}

There are no conflicts of interest

\section{References}

1. Joiner A, Luo W. Tooth colour and whiteness: a review. J Dent. 2017 Dec;67S:S3-10. doi: 10.1016/j.jdent.2017.09.006.

2. International Commission on Illumination. Colorimetry. 4rd ed. Vienna: CIE; 2004.

3. Tao D, Sun JN, Wang X, Zhang Q, Naeeni MA, Philpotts CJ, et al. In vitro and clinical evaluation of optical tooth whitening toothpastes. J Dent. 2017 Dec;67S:S25-8. doi: 10.1016/j.jdent.2017.08.014.

4. Sullivan C, Pan Q, Westland S, Ellwood R. A yellowness index for use in dentistry. J Dent. 2019 Dec;91:103244. doi: 10.1016/j.jdent.2019.103244.

5. Epple M, Meyer F, Enax J. A critical review of modern concepts for teeth whitening. Dent J (Basel). 2019 Aug 1;7(3):79. doi: 10.3390/dj7030079.

6. Jurema AL, Claudino ES, Torres CR, Bresciani E, Caneppele TM. Effect of over-the-counter whitening products associated or not with 10\% carbamide peroxide on color change and microhardness: in vitro study. J Contemp Dent Pract. 2018 Apr;19(4):359-66

7. Joiner A, Philpotts CJ, Ashcroft AT, Laucello M, Salvaderi A. In vitro cleaning, abrasion and fluoride efficacy of a new silica based whitening toothpaste containing blue covarine. J Dent. 2008;36(Suppl 1):32-7. doi: 10.1016/j.jdent.2008.02.003. 
8. Westland S, Luo W, Li Y, Pan Q, Joiner A. Investigation of the perceptual thresholds of tooth whiteness. J Dent. 2017 Dec;67S:S11-4. doi: 10.1016/j.jdent.2017.09.013.

9. Vaz VTP, Jubilato DP, Oliveira MRM, Bortolatto JF, Floros MC, Dantas AAR, et al. Whitening toothpaste containing activated charcoal, blue covarine, hydrogen peroxide or microbeads: which one is the most effective? J Appl Oral Sci. 2019 Jan;27:e20180051. doi: 10.1590/1678-7757-2018-0051.

10. Münchow EA, Hamann HJ, Carvajal MT, Pinal R, Bottino MC. Stain removal effect of novel papainand bromelain-containing gels applied to enamel. Clin Oral Investig. 2016 Nov;20(8):2315-20. doi: 10.1007/s00784-016-1840-1.

11. Tao D, Smith RN, Zhang Q, Sun JN, Philpotts CJ, Ricketts SR, et al. Tooth whitening evaluation of blue covarine containing toothpastes. J Dent. 2017 Dec;67S:S20-4. doi: 10.1016/j.jdent.2017.10.014.

12. Perez MM, Pecho OE, Ghinea R, Pulgar R, Della Bona A. Recent advances in color and whiteness evaluations in dentistry. Cdent. 2019;1:23-9. doi: 10.2174/2542579X01666180719125137.

13. Wang $C$, Lucas R, Smith AJ, Cooper PR. An in vitro screening assay for dental stain cleaning. BMC Oral Health. 2017 Jan;17(1):37. doi: 10.1186/s12903-016-0328-3.

14. Lippert F. An introduction to toothpaste - its purpose, history and ingredients. Monogr Oral Sci. 2013;23:1-14. doi: 10.1159/000350456

15. Shamel M, Al-Ankily MM, Bakr MM. Influence of different types of whitening tooth pastes on the tooth color, enamel surface roughness and enamel morphology of human teeth. F1000Res. 2019 Oct 16:8:1764. doi: 10.12688/f1000research.20811.1.

16. Vertuan M, de Souza BM, Machado PF, Mosquim V, Magalhães AC. The effect of commercial whitening toothpastes on erosive dentin wear in vitro. Arch Oral Biol. 2020 Jan;109:104580. doi: 10.1016/j.archoralbio.2019.104580.

17. Odilon NN, Lima MJP, Ribeiro PL, Araújo RPC, Campos EJ. [In vitro evaluation of the effect of bleaching dentifrices containing blue covarine on bovine dental enamel]. Rev Odontol UNESP. 2018;47(6):388-94. Portuguese. doi:10.1590/1807-2577.1211.

18. Chang JY, Chen WC, Huang TK, Wang JC, Fu PS, Chen JH, et al. Evaluating the accuracy of tooth color measurement by combining the Munsell color system and dental colorimeter. Kaohsiung J Med Sci. 2012 Sep;28(9):490-4. doi: 10.1016/j.kjms.2012.04.006.

19. Carlos NR, Pinto A, do Amaral F, França F, Turssi CP, Basting RT. Influence of staining solutions on color change and enamel surface properties during at-home and in-office dental bleaching: an in situ study. Oper Dent. 2019 Nov/Dec;44(6):595-608. doi: 10.2341/18-236-C.

20. Bergesch V, Henrique F, Aguiar B, Turssi CP, Mantovani F, França G, et al. Shade changing effectiveness of plasdone and blue covarine based whitening toothpaste on teeth stained with chlorhexidine and black tea. Eur J Dent. 2017;11(4):432-7. doi: 10.4103/ejd.ejd_97_17.

21. Malekipour M, Norouzi Z, Shahlaei S. Effect of Remineralizing agents on tooth color after home bleaching. Front Dent. 2019 May-Jun;16(3):158-65. doi: 10.18502/fid.v16i3.1586.

22. Pirolo R, Mondelli RF, Correr GM, Gonzaga CC, Furuse AY. Effect of coffee and a cola-based soft drink on the color stability of bleached bovine incisors considering the time elapsed after bleaching. J Appl Oral Sci. 2014 Nov-Dec;22(6):534-40. doi: 10.1590/1678-775720130578. 